\title{
A low-cost, low-drain signal generator for time-sampling observation
}

\author{
CHARLES E. AYLWORTH and RONALD J. STOVALL \\ Naval Ammunition Depot, Applied Sciences Department, Crane, Indiana 47522
}

A battery-powered interval timer is described. The low-cost circuit is detailed.

Time-sampling procedures often require the observer to record data at some regular interval. A common practice is to place a tining device in the observer's field of view or to generate an auditory event marker at the specitied interval. Reynierse and Toevs (1973) observe that such event marking devices often hamper observation by creating a distraction for the subjects, or by being large and unwieldy. They make a strong case for the need for improved interval marking devices.

Reynierse and Toevs (1973) present a simple device. based on integrated circuit timers, which generates a continuous string of tone bursts (or "chirps") at a predetermined rate. These chirps may be presented either to the experimenter via an earphone or at large through a small speaker. Their design has the desirable leatures of simple construction. low cost. self-contained battery operation. small size, continuously adjustable inter-pulse-interval (from .2 to $30 \mathrm{sec}$ ). and a separately adjustable pulse duration. How ever. since their design uses one integrated circuit wired as a tree-running, asymmetric, astable multivibrator, it is not conservative of energy, leading to a relatively short battery life.

The present paper presents a circuit which retains the desirable characteristics of the device described by Reynierse and Toevs (1973) while making several important improvements. It is extremely conservative of battery life and includes a circuit element that assures that timing accuracy is maintained and that the battery will not go dead in the middle of an experimental session. An additional modification permits the preprogramming of four timing intervals, and is discussed in detail in a later section of this paper. The present device is slightly more difficult to construct than that of Reynierse and Toevs (1973). but is well within the abilities of any technician with more than rudimentary experience in the construction of solid state electronic devices.

At the heart of the present device (see Figure 1) is a programmable unijunction transistor (PUT) manu-

This research was sponsored by the Commanding Officer, Naval Ammunition Depot. Crane, Indiana. in conjunction with the project entitled. "Effects of Demolition Operations at NAD cranc." factured. as are all semiconductors listed, by the General Electric Company (No. 2N6028). With the exception of the PUT (Q1). the exact characteristics of the semiconductors are not critical, and any element of the same general class may be substituted for the semiconductors specitied.

The device is essentially two relaxation-type oscillators. One. using Q1. generates the inter-pulseinterval; the second. incorporating $Q 4$, generates the sawtooth waveform that produces the audible tone. $Q S$ is an emitter-follower necessary to drive the high-impedance earphone. The timing is controlled by $\mathrm{Cl}$ and $\mathrm{RA}$. which represents the total resistance between the anode of Q1 and the positive pole of the power source $\left(+V_{c c}\right)$. RA is a potentiometer which allows the timing interval to be varied. When the triggering voltage for $\mathrm{Q} 1$ is reached by $\mathrm{C} 1$. Q 1 produces a pulse that triggers $Q 2$ to its conducting state. Q2 remains in its conducting state until the discharge current from $\mathrm{C} 3$ drops below the holding current of $Q 2$. When $Q 2$ conducts. $\mathrm{C} 3$ and $\mathrm{C} 6$ are discharged and Q3 is changed to its nonconductive state. When Q3 is conductive, Q4 will not oscillate, since $R 8$, the timing resistance, is connected to a low voltage at the collector of Q3. A low current through R6 holds Q3 conductive until C3 discharges through Q2. When Q3 is nonconductive, Q4 oscillates at a frequency determined by $\mathrm{R} 7, \mathrm{R} 8$, and $\mathrm{C} 4$. The tone burst duration is determined by the size of $\mathrm{C} 3$. The battery test switch bypasses $Q 1$, sending a continuous pulse to Q2 via a voltage-dropping potentiometer.

Components required for each basic unit include: One 47-ohm resistor (R1), three $22 \mathrm{~K}$ resistors ( $R 2$, $R 3 . R 10$ ), one $10 \mathrm{~K}$ potentiometer (R4), one $47 \mathrm{~K}$ resistor (R5). two $330 \mathrm{~K}$ resistors ( $R 6, R 12)$, one $10 \mathrm{~K}$ resistor ( $R 7)$, one $56 \mathrm{~K}$ resistor $(\mathrm{R} 8)$, one $1.5 \mathrm{~K}$ resistor (R9), one $5.6 \mathrm{~K}$ resistor (R11), one $3 \mathrm{M}$ potentiometer (RA) (all resistors may be $1 / 2$ or $1 / 4 \mathrm{~W}$ ), two $30 \mu \mathrm{F} / 15 \mathrm{~V}$ capacitors (C1, C3), one .002- $\mu \mathrm{F}$ capacior $(\mathrm{C} 2)$, one $.01-\mu \mathrm{F}$ capacitor $(\mathrm{C} 4)$, one $.05-\mu \mathrm{F}$ capacitor ( $(5)$, and one $3.0-\mu \mathrm{F}$ capacitor $(\mathrm{C} 6)$. The semiconductors required are all listed by General Electric manufacturer's number. Except for the PUT, any similar component may be substituted with acceptable results. The semiconductors required are: one $2 \mathrm{~N} 6(028$ programmable unijunction transistor 

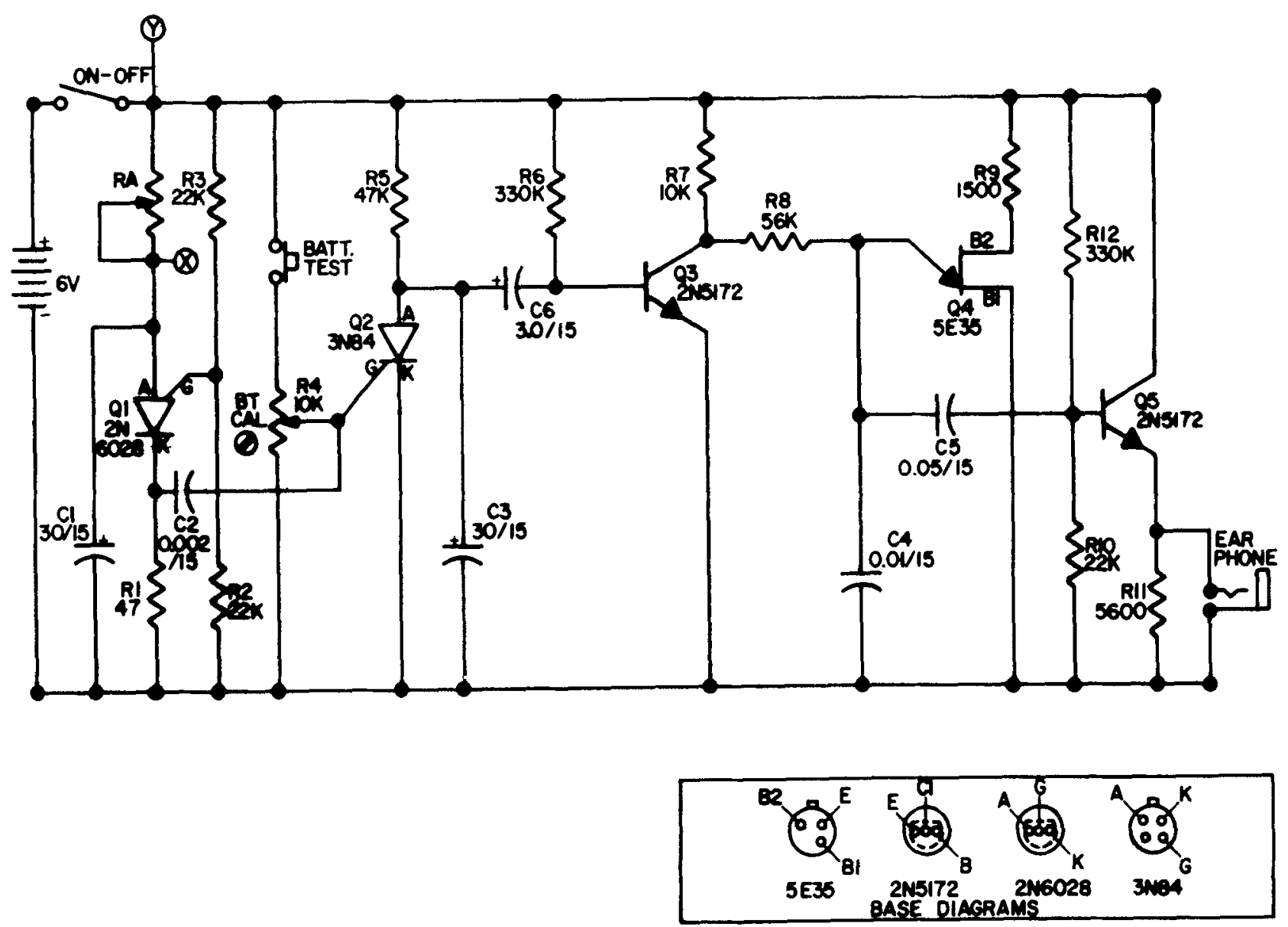

Figure 1. Schematic diagram for single-interval signal generator unit.

(Q1), one 3N84 silicon-controlled switch (Q2), two 2N5172 NPN transistors (Q3, Q5), one 5E35 unijunction (Q4). Miscellaneous hardware required includes: one SPST subminiature switch (ON-OFF), one SPST subminiature push button (battery test), one miniature earphone and jack, four $1.5-\mathrm{V}$ batteries and clip (a $9 . \mathrm{V}$ battery may be substituted), a $25 \mathrm{x}$ $50 \mathrm{~mm}$ piece of epoxy circuit board, and an LMB No. 772 Tite-Fit chassis box. Most of the electronic components are common to many laboratories. and all are easily available at any electronic supply house. If available, an aluminum case designed to hold a pack of cigarettes makes a superior housing. The cigarette case is not only large enough, but is lightweight and has rounded corners that slip snoothly into a shirt pocket. Built into a cigarette case, with the multi-interval improvement described in subsequent paragraphs, powered by four Mallory Duracell alkaline batteries, the unit measures $88 \times 58$ x $28 \mathrm{~mm}$ and weighs $160 \mathrm{~g}$. Two completed units are shown in Figure 2.

Many experinenters have occasion to make observations at several different sampling rates. A simple moditication to the circuit in Figure 1 can add this feature with very little extra effort. The on-off

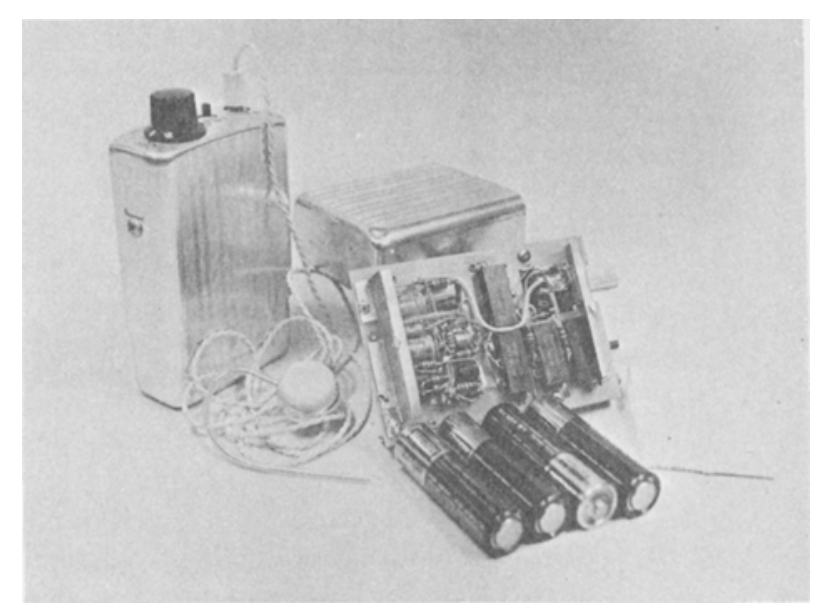

Figure 2. Two assembled units, one removed from its case to show circuit and battery placement. Black flat rectangles are the interval adjustment potentiometer (RAs). Note size relative to match pack. 


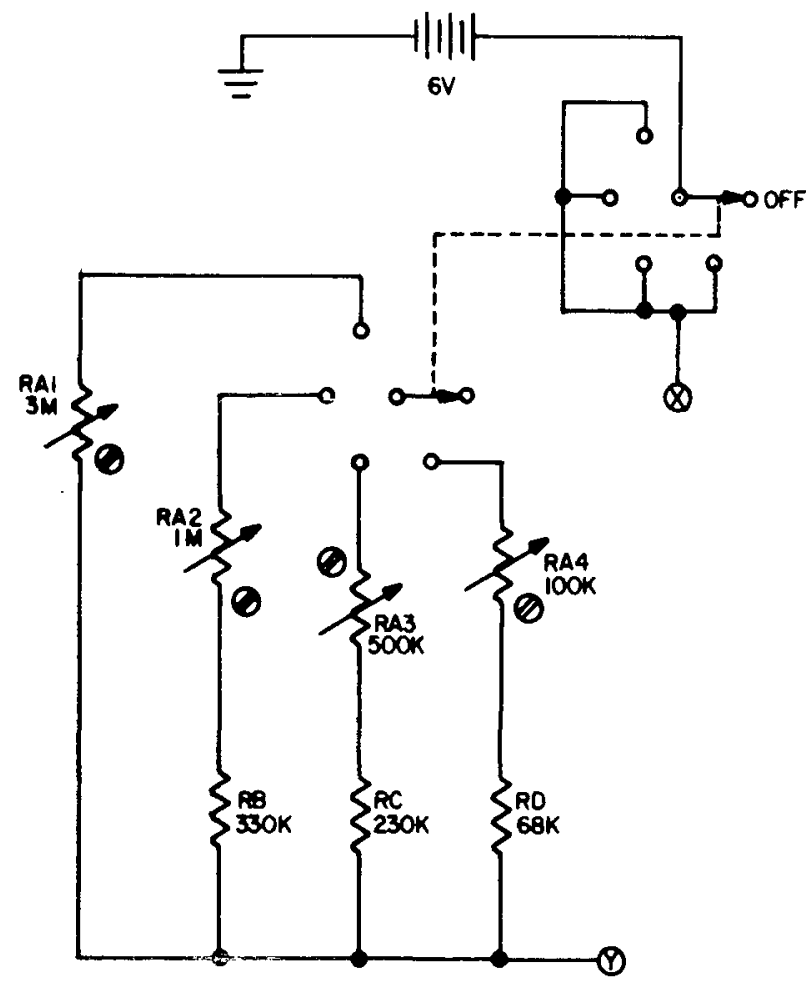

Figure 3. Schematic diagram for multiple-interval modification.

switch is replaced by one set of poles of a five-position double-pole rotary gang switch. Four potentiometers (RA1. RA2. RA3. RA4) are connected to weighting resistors (RB. $R C, R D$ ) and substituted for $R A$ in Figure 1 by means of the second set of poles on the rotary switch. This substitution is made at comnections " $X$ " and " $Y$ " in Figure 1. Figure 3 presents a schematic drawing of this modification. Of course. any number of RAs can be included; however. there is scant room for more than three additional potentiometers in the case currently in use. With this moditication. a unit will cost under $\$ 10$ for parts.

The PUT has the special function of triggering at an anode potential proportional to the voltage applied to the gate terminal. This means that it will oscillate accurately at any voltage from above 9 to below $4.5 \mathrm{~V}$. at a rate determined by the timing $\mathrm{R}-\mathrm{C}$ circuit. Thus. the preset intervals will remain stable as the battery voltage declines with use. The battery test circuit ensures both that the battery voltage is high enough for accurate operation of the PUT and, indirectly, that sulficient battery life remains for at least $1 \mathrm{~h}$ operation. After assembly of the circuit, the battery test circuit must be calibrated. A current-limited $4.5-1 \mathrm{dc}$ power supply should be applied in place of the battery, the unit turned on, the battery test push button depressed, and potentiometer R4 adjusted until the tone is heard in the earphone. R4 is then slowly backed off until the tone ceases. During normal operation, a press on the $B T$ button will produce a tone if the battery is producing better than $4.5 \mathrm{~V}$. With the low drain of this circuit, the experimenter can be sure that the intervals will be produced with nominal accuracy for at least $1 \mathrm{~h}$.

The 3M potentiometer (RA) will provide a continuously adjustable interval of from 1 to $60 \mathrm{sec}$. With the resistances specified in Figure 2, a realm of intervals from 1 to $60 \mathrm{sec}$ may be preset (RA4 should be set to the shortest interval. RA1 to the longest). The nominal replication deviation will be less than $2 \%$ of the repetition interval (about $1.2 \mathrm{sec}$ for a 1 -min interval). Intervals longer than $60 \mathrm{sec}$ may be obtained by replacing $\mathrm{C} 1$ with up to a $100 \mu \mathrm{F} / 15 \mathrm{~V}$ electrolytic capacitor. A limit is imposed by leakage from $\mathrm{Cl}$, and intervals in excess of $3 \mathrm{~min}$ are liable to be highly inaccurate. The tone burst will have a frequency of about $1.5 \mathrm{KHz}$. The frequency may be varied throughout a range of from $400 \mathrm{~Hz}$ to about $10 \mathrm{KHz}$, by changing $\mathrm{R} 8$ and $\mathrm{C} 4$. The tone burst duration is presently about $.7 \mathrm{sec}$. It may be varied from about $100 \mathrm{msec}$ to about $1 \mathrm{sec}$ by changing $\mathrm{C} 3$. The circuit has been designed for $6 \mathrm{~V}$, a $9-\mathrm{V}$ battery may be used, but R5 must be increased, R4 may require adjustment, and $9 \mathrm{~V}$ will change the characteristics of the tone burst.

As Reynierse and Toevs (1973) assert, these devices have many uses in the laboratory, classroom, and industrial environments. The present circuit has been tested with a continuous operation period of $1,500 \mathrm{~h}$. and used for about 200 additional hours on an intermittent schedule, with its original set of heavy duty batteries. The unit has been found to be insensitive to temperature variation, remaining highly accurate under all conditions of use. As yet, the effective battery life has not been reached. With the multiple-interval moditication, it has been found to be convenient. rugged, dependable, and versatile. This is truly an "ideal" signal generator for human factors tield or laboratory investigations.

\section{REFERENCE}

Reynierse, J. H., \& Toevs, J. W. An ideal signal generator for time-sampling observation procedures. Behavior Research Methods \& Instrumentation, 1973, 5, 57-58.

(Received for publication November 19, 1974; revision received January 17,1975 .) 